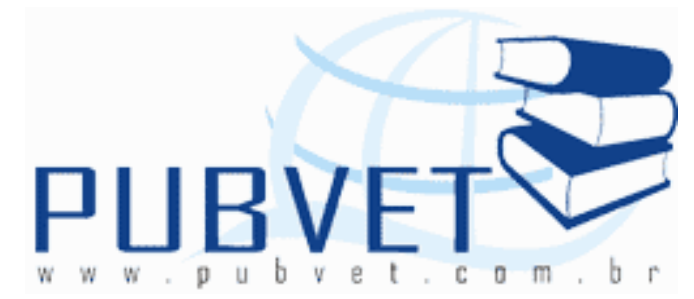

PUBVET, Publicações em Medicina Veterinária e Zootecnia.

\title{
Métodos de esterilização utilizados na indústria farmacêutica, farmácias, laboratórios e clínicas veterinárias
}

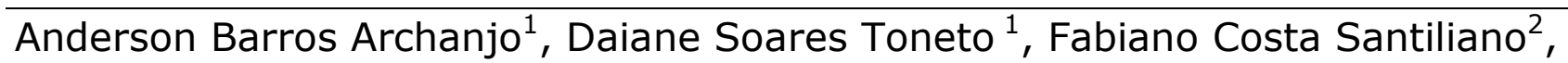 Olavo dos Santos Pereira Júnior ${ }^{3}$, Bethânia Ribeiro de Almeida ${ }^{4}$}

1 Graduandos do Curso de Farmácia. Centro de Ciências Agrárias da Universidade Federal do Espírito Santo

2 Mestre em Biociências e Biotecnologia. Centro de Ciências Agrárias da Universidade Federal do Espírito Santo. fabianosantiliano@yahoo.com.br

3 Professor Doutor do Departamento de Farmácia e Nutrição. Centro de Ciências Agrárias da Universidade Federal do Espírito Santo. olavoufesjr@gmail.com

4 Professora Mestre do Curso de Farmácia. Centro de Ciências Agrárias da Universidade Federal do Espírito Santo - CCA-UFES, Cx. Postal 16, Alegre, Espírito Santo. bethaniaralmeida@yahoo.com.br

\section{Resumo}

O processo de preparação de um medicamento envolve varias etapas que podem interferir diretamente na qualidade final do produto e sua eficácia no organismo. A segurança e eficácia terapêutica sofrem impacto das operações farmacêuticas realizadas no decorrer do processo. Entre esses processos encontra-se a esterilização, que compreende a destruição de todas as formas de vida microbiana mediante a aplicação de agentes físicos, químicos e físico- 
químicos. Dependendo do artigo, material ou substância a ser esterilizado, utiliza-se um método distinto, observando se estes materiais suportam ou não o calor, vapor ou ambos. O objetivo deste trabalho foi analisar os principais métodos de esterilização existentes e apontar os mais adequados para utilização nas indústrias farmacêuticas, farmácias, laboratórios e clinicas veterinárias.

Palavras-chave: esterilização, farmácia, indústria farmacêutica, laboratório, clínica veterinária.

\title{
Sterilization methods used in the pharmaceutical industry, pharmacies, laboratories and veterinary clinics
}

\begin{abstract}
The process for preparing a medicinal product involves several steps that can interfere directly in the final product quality and its efficacy in the body. The safety and efficacy are impacted pharmaceutical operations performed during the process. Among these processes is sterilization, which comprises the destruction of all microbial life forms by the application of physical, chemical and physic-chemical. Depending on the article, material or substance to be sterilized, it uses a different method, noting that these support materials or non-heat, steam or both. The objective of this study was to analyze the major existing sterilization methods and point out the most suitable for use in the pharmaceutical, pharmacies, laboratories and veterinary clinics.
\end{abstract}

Keywords: sterilization, pharmacy, pharmaceutical industry, laboratory, veterinary clinic.

\section{1- INTRODUÇÃO}

O processo de preparação de um medicamento envolve várias etapas que podem interferir diretamente na qualidade final do produto e sua eficácia no organismo. A segurança, eficácia terapêutica e assimilidade sofrem impacto 
das operações farmacêuticas realizadas no decorrer do processo (FERREIRA, 2010).

As operações farmacêuticas estão divididas em dois grupos, as físicas e as mecânicas. As operações físicas são aquelas que promovem alteração do estado físico do fármaco ou da droga empregada, enquanto que, quando a droga ou o fármaco passam por processos que alteram o aspecto exterior sem alterar o seu estado físico ou constituição química, refere-se a uma operação mecânica (FERREIRA, 2010).

Dentre as essas operações unitárias farmacêuticas físicas, destaca-se o processo de esterilização, que compreende a destruição de todas as formas de vida microbiana (vírus, bactérias, esporos, fungos, protozoários e helmintos), mediante a aplicação de agentes físicos, químicos e físico-químicos (MOZACHI, 2007), e, apresenta como objetivo, incapacitar a reprodução de todos os organismos presentes no material a ser esterilizado, promovendo a morte microbiana até que a probabilidade de sobrevivência do agente contaminante seja menor que 1:1.000.000, quando um objeto pode ser considerado estéril. (DE SOUZA, 2007 ). Dependendo do artigo, material ou substância a ser esterilizado, utiliza-se um método adequado, observando se estes materiais suportam ou não o calor, vapor ou ambos (MOZACHI, 2007). FERREIRA (2010) define o processo de esterilização como a ausência de organismos viáveis, podendo ser realizado por diferentes métodos como calor úmido, calor seco, irradiação, gases antissépticos, filtração e altas pressões hidrostáticas. É válido enfatizar, que de acordo com ROMANO (2007), oparâmetro utilizado na certificação da esterilização refere-se ao esporo bacteriano, considerado a forma mais resistente dos agentes esterilizantes, assim, a garantia de um processo de esterilização de um artigo é representado pela destruição de todos os esporos.

De acordo com YAMAMOTO e colaboradores (2004), as contaminações dos medicamentos, durante a etapa de manipulação, causam alterações dos requisitos técnicos como as características sensoriais, degradação de componentes da formulação, alterações físicas e da aparência do produto. 
Assim, os tornam impróprios para o consumo, considerando à perda da eficácia e segurança, podendo causar danos à saúde dependendo do tipo do microrganismo presente, da via de administração utilizada e o estado de saúde do usuário do produto (BAZZO et al., 2010).

No sentido de garantir a segurança dos fármacos produzidos, o processo de esterilização, tem como intuito, destruir as formas de vida microbiana tida como nocivas para o restabelecimento da saúde. Sabe-se que a utilização de reprocessamentos adequados e métodos seguros de esterilização garantem uma melhoria contínua na assistência a saúde da população e reduzem riscos e custos inerentes às infecções hospitalares (BARBOSA \& SARTORI, s/d).

Relativamente ao equipamento veterinário usado, inclusive, na vacinação, deve ser previamente sujeito a inspecção visual e mecânica, sendo devidamente esterilizado e lubrificado.

Dessa forma, o objetivo deste trabalho foi verificar os métodos de esterilização existentes e apontar os mais adequados para utilização nas indústrias farmacêuticas, farmácias de manipulação, laboratórios e clínicas veterinárias.

\section{2- MÉTODOS DE ESTERILIZAÇÃO}

Segundo ROMANO (2007), a esterilização revela-se essencial, pois através dela se consegue destruir microrganismos de objetos, roupas, equipamentos e outros materiais médicos que entram em contato direto ou indireto com pacientes, evitando assim a contaminação em procedimentos cirúrgicos, curativos ou na realização de quaisquer outros procedimentos, evitando por conseguinte, a transmissão de doenças. Neste sentido, é necessário observar vários fatores como, as características dos microorganismos, o grau de resistência das formas vegetativas, a resistência das bactérias produtoras de esporos e o número de microorganismos e da característica do agente empregado para a esterilização, para que estas técnicas sejam eficazes (MORIYA \& MÓDENA, 2008). 
Assim, a operação unitária farmacêutica de esterilização pode ser realizada por três métodos: os físicos (via calor e/ou umidade), os químicos (como os aldeídos) e os físico-químicos (como o óxido de etileno), sendo abaixo descritos os principais métodos de esterilização aplicados à indústria farmacêutica, clínicas e hospitais veterinários.

\section{1- MÉTODOS FÍSICOS}

Os métodos físicos são subdivididos conforme formas de temperatura (calor seco), umidade (calor úmido), exposições a radiações (ionizantes e não ionizantes) e filtração. O calor não representa somente o agente esterilizante mais usado como também o mais econômico e mais fácil de controlar, assim, vale ressaltar que a ação letal do calor é uma relação tempo-temperatura, dependente de fatores que definem a intensidade do tratamento e do tempo de exposição ao calor para reduzir a população microbiana a níveis estabelecidos (LETRARI et al., 2006). Todavia, conforme MOZACHI (2007), no caso da utilização pelos métodos físicos, os processos combinatórios de calor e umidade representam maior segurança e eficácia.

\subsection{1 - Calor seco}

De acordo com MORIYA \& MÓDENA (2008), o calor seco age oxidando os constituintes químicos dos microorganismos. Porém, a susceptibilidade dos organismos ao calor é muito variável e dependem de alguns fatores, e dentre eles citam-se:
a) Variação individual de resistência,
b) Capacidade de formação de esporos,
c) Quantidade de água do meio,
d) $\mathrm{pH}$ do meio,
e) Composição do meio.

Este método é reservado somente aos materiais sensíveis ao calor úmido. Guarda suas vantagens na capacidade de penetração do calor e na não 
corrosão dos metais e dos instrumentos cortantes, sendo, porém método que exige tempo de exposição para alcançar seus objetivos, por oxidação dos componentes celulares. Os meios utilizados para a esterilização através de calor seco são a estufa e a flambagem (KALIL \& COSTA, 1994). Vale destacar que no caso da esterilização de implantes de silicone, estes métodos de esterilização empregados, por fazer uso de temperaturas elevadas, podem promover a hidrólise e/ou fusão da matriz do polímero, comprometendo a biocompatibilidade dos implantes (AZEVEDO et al., 2006).

\subsubsection{1- Estufa}

A estufa consiste em uma caixa com paredes duplas, entre as quais circula ar quente, proveniente de uma chama de gás ou de uma resistência elétrica. A temperatura interior é controlada por um termostato (MORIYA \& MÓDENA, 2008).

A esterilização em estufas é um processo simples, onde o calor seco se difunde bem, porém penetra com mais dificuldade nos artigos. Isso ocorre devido à dificuldade relativa do ar como o meio de transferência de calor, dessa forma o processo necessita de temperaturas mais altas e maior tempo de exposição (MOZACHI, 2007). O binômio tempo e temperatura devem ser extremamente observados, uma vez que grandes volumes de artigos, influenciam no tempo em que o calor irá atingir a parte central. A grande maioria das vidrarias é esterilizada dessa forma (TRABULSI et al, 1999). Amplamente utilizada em materiais anidros como óleos, pós e pomadas (MOZACHI, 2007).

\subsubsection{2 - Flambagem}

Segundo TRABULSI et al (1999) a flambagem é a forma mais simples de esterilização utilizando o calor seco. A incineração afeta aos microorganismos de forma muito parecida a como afeta as demais proteínas, estes são carbonizados ou consumidos pelo calor (MORIYA \& MÓDENA, 2008). A chama 
direta é utilizada em laboratórios de microbiologia para e esterilização de alças de platina antes e depois da transferência de massas microbianas.

\subsection{2 - Calor úmido}

Quando comparado ao calor seco, este método apresenta maior efetividade, tendo em vista a utilização de temperaturas mais baixas, e, do curto período de tempo necessário para garantir o nível de esterilidade almejado (MASTROENI, 2004; PELCZAR et al.,1996).

A esterilização por calor úmido pode ser feita de duas formas, pela fervura ou por vapor saturado sob pressão (autoclave), onde ambos atuam na desnaturação irreversível das estruturas protéicas dos microorganismos (MOZACHI, 2007). Nesta técnica se associam altas temperaturas com uma elevada taxa de umidade, sendo requeridas assim temperaturas superiores ao ponto ebulição da água (TRABULSI et al., 1999).

\subsubsection{1 - Fervura}

A fervura foi um método correntemente usado na prática diária, mas não oferece uma esterilização propriamente dita, pois a temperatura máxima que pode atingir é $100^{\circ} \mathrm{C}$ ao nível do mar, e é sabido que os esporos, e alguns vírus, resistem a essa temperatura, alguns até por $45 \mathrm{~h}$. Neste processo, devem-se eliminar as bolhas, pois estas protegem as bactérias - no interior da bolha impera o calor seco, e a temperatura de fervura $\left(100^{\circ} \mathrm{C}\right)$, este calor é insuficiente para a esterilização e eliminar as substâncias gordurosas e protéicas dos instrumentos, pois estas impedem o contacto direto do calor úmido com as bactérias (MORIYA \& MÓDENA, 2008).

\subsubsection{Vapor saturado sob pressão}

A esterilização por calor úmido parte do princípio básico da exposição dos artigos a vapor seco saturado em temperatura, pressão e tempo necessário. Entende-se por vapor seco saturado, aquele que toda a água possível está 
contida na forma de vapor transparente, não contendo gotículas de água (MOZACHI, 2007).

O vapor quente sob pressão é o método mais usado para esterilização, por ser atóxico, de baixo custo e por eliminar de forma eficaz os esporos. Dessa maneira, é utilizado em todos os itens que não sejam sensíveis ao calor e à umidade. É processado em autoclaves, em que o calor úmido, gerado por este equipamento, destrói os microorganismos por coagulação e desnaturação irreversíveis de suas enzimas e proteínas estruturais (KALIL \& COSTA, 1994). Com a da difusão do vapor para o interior da membrana celular (osmose), ocorre hidratação do protoplasma celular, produzindo alterações químicas (hidrólise) e coagulando mais facilmente o protoplasma (MORIYA \& MÓDENA, 2008). De acordo com OPPERMANN (2003), este método por atuar por vapor de água, permite atingir todas as arestas e ângulos do equipamento de uso veterinário, possibilitando inclusive esterilização de materiais plásticos, não resistentes aos demais métodos físicos citados nexte texto.

A autoclave consiste em uma caixa metálica de paredes duplas, delimitando assim duas câmaras; uma mais externa que é a câmara de vapor, e uma interna, que é a câmara de esterilização ou de pressão de vapor. A entrada de vapor na câmara de esterilização se faz por uma abertura posterior e superior, e a saída de vapor se faz por uma abertura anterior e inferior, devido ao fato de ser o ar mais pesado que o vapor (MORIYA \& MÓDENA, 2008).

Existem dois tipos de autoclave, a gravitacional e a de alto vácuo. O que as diferencia é o modo como é feita a retirada do ar. Na gravitacional, o ar frio, por se mais pesado, concentra-se na parte inferior da câmara. Assim a sua drenagem ocorre de maneira relativamente mais rápida, porém a retirado do ar de artigos porosos é mais lenta. Na autoclave de alto vácuo, quase todo ar (98\%) é retirado da câmara antes da admissão do vapor. A penetração do vapor é quase imediata, o que reduz o tempo de exposição e a retirada posterior da umidade dos artigos (MOZACHI, 2007). 
Na autoclave emprega-se vapor de água saturado sob pressão e a esterilização ocorre à temperatura de $121^{\circ} \mathrm{C}$ por período de 15 a 30 minutos. Nos aparelhos de alto vácuo, utiliza-se 132 a $1350^{\circ} \mathrm{C}$ (30 libras de pressão) por 4 a 6 minutos (JORGE, 2002).

A esterilização é mais facilmente atingida quando os organismos estão em contato direto com o vapor ou contidos em pequenos volumes líquidos. $O$ processo de autoclavagem é utilizado na esterilização de meios de cultura, instrumentos cirúrgicos, soluções e uma variedade de outros artigos que suportem altas temperaturas e taxas de umidade (TRABULSI et al, 1999). Dessa forma consiste no método físico que maior apresenta eficácia e segurança (MOZACHI, 2007), todavia, para essa garantia de segurança é indicado a identificação dos materiais a serem autoclavados constando de fitas termoresistentes (DE SOUZA, 2007).

Estas fitas podem representar caráter somente para identificação do tipo de material a ser esterilizado, como também com caráter de indicador biológico de qualidade do funcionamento do equipamento. $O$ indicador biológico, como exemplo do Bacillus stearothermophilus, representa um preparado de microrganismo específico, resistente a um determinado processo de esterilização, quando usado na forma adequada quantifica satisfatoriamente a eficiência do processo de esterilização através da integração dos fatores letais de tempo e de temperatura, sobre determinada população microbiana, apresentando a função de estabelecer, avaliar e monitorar os parâmetros físicos do ciclo de esterilização para o equipamento definido, qualificando assim, o nível de esterilidade e registrandor a eficiência do processo (LETRARI et al., 2006).

\subsection{3 - Radiações}

A energia radiante aplicada com favoráveis resutados no processo de esterilização de materiais cirúrgicos descartáveis, vacinas, soros, cosméticos, produtos alimentícios e materiais expostos aos materiais biológicos nos últimos anos (GUIDOLIN et al, 1988). Além disso, a irradiação torna-se um tratamento 
comum para esterilização de ebalagens de alimentos, em processamento asséptico, e produtos farmacêuticos (HAJI-SAEID, SAMPA \& CHMIELEWSKI, 2007). Vale ressaltar que trata-se de um método que pode ser aplicado sobre duas formas: radiações ionizantes e não-ionizantes (MORIYA \& MÓDENA, 2008).

Assim, a radiação, de uma forma geral, revela-se como uma alternativa na esterilização de artigos termossensíveis, atuando em baixas temperaturas, todavia, demonstra-se um método disponível para a escala industrial, considerando os elevados custos de implantação e controle (MORIYA \& MÓDENA, 2008).

\subsubsection{1 - Radiações ionizantes}

A radiação ionizante, aplicada há alguns anos na prática de esterilização de distintos produtos de consumo humano e animal, trata-se de um método de alto custo frente aos demais métodos de esterilização disponíveis, todavia, apresenta ampla utilização para tecidos destinados a transplantes, produção de fármacos e outros (KALIL \& COSTA, 1994). Os raios ionizantes atuam diretamente no DNA, impedindo sua replicação, transcrição e tradução, inviabilizando a vida dos microorganismos (HAJI-SAEID, SAMPA \& CHMIELEWSKI, 2007). Os raios podem ser do tipo beta e gama, provenientes do cobalto, e alfa e $X$, oriundos do tungstênio. Apresentam alta penetrabilidade nos artigos a serem esterilizados (MORIYA \& MÓDENA, 2008).

Vale destacar que a energia eletromagnética derivada de cobalto, radiação gama, é a que se utiliza com maior freqüência na esterilização de alimentos, cosméticos e derivados do sangue, a qual, não aquece o produto, podendo, assim, ser também aplicada a produtos biológicos como dos soros terapêuticos e algumas vacinas, que, na maioria das vezes, são susceptíveis a temperaturas relativamente elevadas. Além disso, a radiação gama, devido ao seu elevado poder de penetração, esteriliza os produtos após o envasamento e, inclusive, após ter sido acondicionado em embalagens habituais (GUIDOLIN et al, 1988), eliminando os riscos de contaminações frente ao processo de 
ampolamento dos medicamentos e fármacos, obedecendo assim os critérios da Farmacopéia Brasileira (1988).

\subsubsection{2 - Radiações não-ionizantes}

$\mathrm{Na}$ radiação não-ionizante são empregados os raios ultravioletas e infravermelhos. Tem seu uso vetado pela Portaria 930/92 do Ministério da Saúde, quando aplicado na desinfecção e esterilização de superfícies. É tóxico aos olhos e pele. Atuam como bactericidas, ao lesarem o DNA dos microorganismos. Porém, para que os raios tenham efeito faz-se necessário que os mesmos incidam perpendicularmente em superfícies extremamente lisas e planas. Tem sua potência reduzida pelo ar e pela água (MOZACHI, 2007).

\subsection{4 - Filtração}

A filtração consiste na passagem de soluções ou gases por filtros suficientemente pequenos para reterem os microorganismos, como bactérias e fungos, portanto os vírus passam por esses filtros. Utilizado na remoção de bactérias de fluídos farmacêuticos termolábeis que não podem ser esterilizados de outra forma (KALIL \& COSTA, 1994). Também empregados na entrada de ar de salas e ambientes estéreis (TRABULSI ET al., 1999).

É importante destacar que na dependência do tipo de produto e dos filtros esterilizantes usados, o processo é relativamente demorado e, invariavelmente, ocorrem perdas de volumes que são, às vezes, consideráveis, no processo de esterilização de de soros terapêuticos e de algumas vacinas não adicionadas de adjuvantes. Vale informar também que alguns vírus e micoplasmas, estes em certos estágios do seu desenvolvimento, passam através de membranas inertes ou placas de filtros esterilizantes de profundidade., assim, na produção em escala industrial de vacinas virais, em cultivos celulares, é relativamente freqüente a constatação de contaminações do soro normal utilizado 
por vírus estranhos e, especialmente, por micoplasmas (GUIDOLIN et al, 1988).

\section{2 - MÉTODOS QUÍMICOS}

Diversas são as substâncias químicas utilizadas na esterilização, normalmente aplicadas por período de seis a dez horas (KALIL \& COSTA, 1994). Estas podem ser líquidas ou gases que matam ou danificam irreversivelmente a estrutura dos microorganismos, sendo os principais agentes empregados os grupos orgânicos aldeídos e ácidos (MOZACHI, 2007).

Embora a esterilização utilizando agentes químicos forneça uma margem de segurança inferior à oferecida pelos métodos físicos, ela representa um relevante método alternativo de esterilização, considerando que muitos materiais não podem ser esterilizados pelo calor seco ou calor úmido a alta pressão de vapor, como no caso dos produtos termossensíveis (FARIA et al., 1998).

De acordo com dados da literatura muitos são os fatores que interferem na esterilização química, como no caso da temperatura, da concentração do princípio ativo, da umidade, do tempo de exposição, do $\mathrm{pH}$, da presença de matéria orgânica, dentre outras (KOSTENBAUER, 1977; CRÉMIEUX E FLEURETTE, 1983).

\subsection{1 - Aldeídos}

\subsubsection{1 - Formaldeídos}

Empregado nas formas de desinfetante e esterilizante, por um período de 18 horas (MORIYA \& MÓDENA, 2008) são comumente encontrados sob a forma de formalina, sendo esta sua diluição aquosa a 37\%. Esta formulação demonstra-se um potente bactericida e fungicida, agindo também contra vírus, bacilos da tuberculose e esporos bacterianos (MOZACHI, 2007), atua alcalinizando determinados grupos das proteínas e das purinas (KALIL \& 
COSTA, 1994), envolvendo a alquilação entre a aldoxila e os átomos de hidrogênio dos radicais amino $(-\mathrm{NH} 2)$; hidroxila $(-\mathrm{OH})$, carboxila $(-\mathrm{COOH})$ e sulfidrila (-SH) das proteínas e ácidos nucleicos microbianos, formando pontes metilênicas ou etilênicas que impedem que estes componente vitais cumpram suas funções celulares (FARIA et al., 1998).

Preferido pelo seu baixo custo, pequeno risco de explosão e baixa ação residual, sendo esse favorecido pela exposição do material ao ar livre após a esterilização (LINE E PICKERILL, 1973). Todavia, apresenta uso limitado, apesar de liberado pela Portaria 930/92 do Ministério da Saúde, por ser iniciador de células cancerígenas (MOZACHI, 2007), além de queratinizar e sensibilizar a pele por contato, possibilitar irritação das mucosas respiratórias e oculares, asma, bronquite e pneumonia, sendo o teor máximo permitido no ar é de 2 ppm (COLLINS, et al., 1981; ZANON e NEVES, 1987; RUTALA, 1987).

Vale destacar que no Brasil, o uso do gás formaldeído obtido por meio de sublimação do paraformaldeído, como método de esterilização, sempre esteve presente nos hospitais, mesmo com o advento do gás óxido de etileno, no entanto, pesquisas sobre condições de esterilização de materiais utilizando esse gás são escassas (FARIA, et al., 1998).

\subsubsection{2 - Glutaraldeído}

Trata-se de um dialdeído saturado largamente aceito como desinfetante de alto nível e quimioesterilizador. Sua ação ocorre em soluções aquosas que apresentem pH alcalino, eliminando assim os esporos bacterianos. Atua alterando os ácidos desoxirribonucléicos e ribonucléicos, bem como a síntese protéica dos microorganismos (KALIL \& COSTA, 1994). Aplicado na concentração de $2 \%$, associada a um antioxidante, por 8 a 12 horas, é usado para esterilizar material de acrílico, cateteres, drenos, nylon, silicone, teflon, PVC, laringoscópios e outros (MORIYA \& MÓDENA, 2008). 


\subsection{2 - Ácidos}

\subsubsection{1- Ácido peracético}

O ácido peracético, utilizado para desinfecção e esterilização de cateteres (portaria 15/1988 do Ministério da Saúde), ao se decompor origina ácido acético, água, oxigênio e peróxido de hidrogênio. Em altas concentrações tem odor pungente e riscos de explosão e incêndio. Age na desnaturação protéica, perda da permeabilidade da membrana celular e oxidam o radical sulfidril e súlfur das proteínas, enzimas e outros metabólitos (MORIYA \& MÓDENA, 2008).

\section{3 - MÉTODOS FÍSICO-QUÍMICOS}

MOZACHI (2007) define os métodos físico-químicos como processos de esterilização realizados a baixas temperaturas, empregado principalmente para materiais sensíveis ao calor, umidade ou ambos. Os métodos mais utilizados são os que têm o óxido de etileno e plasma de peróxido de hidrogênio como agente esterilizador.

\subsection{1 - Óxido de etileno}

Este processo representa um método físico-químico de esterilização, sendo processado em autoclave, sob pressão e temperatura, utilizando um agente químico, o óxido de etileno, como esterilizador (MOZACHI, 2007). Este agente químico que refere-se à um gás incolor, inflamável, tóxico, altamente reativo, e completamente solúvel em água, álcool, éter e muitos solventes orgânicos, borracha, couro e plásticos (MORIYA \& MÓDENA, 2008). Este método, trata-se de uma das principais opções para esterilização de materiais termossensíveis, desde que obedecidos alguns parâmetros relacionados à concentração de gás $(450 \mathrm{mg} / \mathrm{L}$ a $1200 \mathrm{mg} / \mathrm{L})$, temperatura $\left(45\right.$ a $\left.60^{\circ} \mathrm{C}\right)$, 
umidade relativa (20 \% a $40 \%$ ) e tempo de exposição ( 2 a 5 horas) (BARBOSA \& SARTORI, s/d).

Segundo dados da literatura, sugere-se ação alquilante e atividade antimicrobiana, tendo em vista a reação com grupos nucleofílicos das proteínas e bases nitrogenadas, formando ligações irreversíveis que impedem a duplicação do material genético, inviabilizando a síntese protéica e, portanto, a multiplicação celular (MOZACHI, 2007; BARBOSA \& SARTORI, s/d). Assim, revela-se eficaz em temperaturas relativamente baixas, penetrando em substâncias porosas, não sendo corrosivo ou danificante de materiais, agindo rapidamente, e, podendo ser removido de forma rápida (MORIYA \& MÓDENA, 2008), e tem sido amplamente utilizado a nível hospitalar, sendo regulamentado pela Portaria Interministerial 04/1971, dos Ministérios da Saúde e do Trabalho (MOZACHI, 2007).

Apesar de ser considerado um agente bactericida, esporicida e virucida, a esterilização por óxido de etileno, apresenta alto custo de implantação, manutenção e controle, sendo aplicável apenas em materiais que não podem ser submetidos a outros meios de esterilização (MOZACHI, 2007). De acordo com AZEVEDO e colaboradores (2006), a esterilização química gasosa por óxido de etileno, representa a vantagem de propiciar o tratamento eficaz em implantes de silicone, em temperaturas relativamente baixas, porém os resíduos do gás, por serem agentes alquilantes, podem reagir com grupos funcionais do polímero provocando alterações das propriedades do silicone, comprometendo o biomaterial.Além disso, o óxido de etileno, em contato com a água, torna-se uma substância cancerígena, e, considerando tratar-se de poucas empresas atuarem com este processo de esterilização, pelo alto custo, estas firmas normalmente tercerizam esses serviços a indústrias e hospitais, e não aceitam presença de gotículas de água nos materiais a serem esterilizados pelas contratualizações (DE SOUZA, 2007). 


\subsection{2 - Plasma de peróxido de hidrogênio}

$\mathrm{Na}$ esterilização por plasma de peróxido de hidrogênio os instrumentos e dispositivos são reprocessados com segurança e eficácia sem limitações ou os riscos, sendo esse uma eficiente tecnologia a baixa temperatura, pois promove uma esterilização de forma rápida e eficaz (BORBOSA \& SARTORI, s/d).

A tecnologia empregando o plasma de peróxido de hidrogênio tem como princípio uma tríade: um precursor químico representado pelo peróxido de hidrogênio $\left(\mathrm{H}_{2} \mathrm{O}_{2}\right)$, um precursor físico representado por um gerador de ondas eletromagnéticas que originarão o plasma de baixa temperatura (45 a $55^{\circ} \mathrm{C}$ ), quando entrarem em contato com o precursor químico, e o vácuo que é obtido por uma bomba de vácuo de alta efetividade para que o processo possa ter início (BARBOSA \& SARTORI, s/d).

A ação dos radicais livres (gerados a partir do $\mathrm{H}_{2} \mathrm{O}_{2}$ ) como uma tentativa de estabilização, interagirão com moléculas essenciais ao metabolismo e reprodução dos microorganismos, realizando ligações químicas inespecíficas com membranas citoplasmáticas, enzimas, ácido desoxirribonucléico (DNA), ácido ribonucléico (RNA) entre outros, que resultará em uma ação esporicida, fungicida, bactericida e virucida, tornando o processo de esterilização viável em curto espaço de tempo (DEMARZO, 2006).

\section{3- CONSIDERAÇÕES FINAIS}

Diante dos métodos de esterilização apresentados os meios físicos que utilizam o calor seco e úmido como princípios seriam os mais aplicáveis a uma farmácia de manipulação ou laboratórios em geral. Isso se deve ao baixo custo de implantação associado à alta eficácia e segurança oferecidas pelos mesmos.

Em indústrias farmacêuticas ou outras que necessitem de processos de esterilização em grande escala, os métodos físicos por radiação ionizante e os físico-químicos com óxido de etileno ou plasma de peróxido de hidrogênio, seriam os mais recomendados, por atuarem em grande escala e os seus custos com implantação, manutenção e controle serem relativamente altos. 
A busca por novas tecnologias que agreguem eficácia, segurança, e baixo custo são de extrema importância no processo de esterilização.

\section{REFERÊNCIAS BIBLIOGRÁFICAS}

AZEVEDO, J. C.; CRUZ, Á. S.; PINTO, T. J. A. Brazilian Journal of Pharmaceutical Sciences. V. 42, ed. 2, 2006.

BARBOSA, L. S., SARTORI, M. R. K. Métodos de esterilização de artigos hospitalares efetivos contra micobactérias não tuberculosas de crescimento rápido. Cadernos da Escola de Saúde, Curitiba, ano 5, v. 1, p. 170-184, [s/d].

BAZZO, G. C; PEZZINI, B. R; ZÉTOLA, M; NUNES, G. C; PETERS, E. A importância da avaliação da qualidade microbiológica de matérias-primas em farmácias magistrais. Disponível em: <http://images.professorcristiano.multiply.multiplycontent.com/attachment/0/SCyj5AoKCmgA ADrcgbo1/artigoavalia\%20o59ok.doc?nmid=96234578. >. Acesso em 12/01/2012.

COLLINS, C. H., et. al. Desinfectants: their use and evaluation of effectiveness. Academic Press, 1981.

DEMARZO D. A evolução dos esterilizadores a baixa temperatura: plasma de peróxido de hidrogênio. [periódico na Internet]. $2006 \mathrm{Abr}$ [citado 2010 Out 18]; 26: 32 - 38. Disponível em: <http://www.sbcc.com.br/revistas_ pdfs/ed\%2023 /23Artigo TecnicoEsterilizPlasma.pdf>. Acesso em: 17 julho 2012.

DE SOUZA, N.C. Uma aplicação do custeio baseado em atividades na central de materiais esterilizados de hospitais. Revista Multiface. V. 1, ed.. 2, p. 56-66, 2007.

FARIA, M.R.; MILAGRES, A.M.M.; AZZOLINI, V.; NASCIMENTO, L.C.; CHAVASCO, J.K. Avaliação da esterilização de canetas de alta rotação e cabos de bisturi pelo formaldeído a temperatura de $37^{\circ} \mathrm{C}$. Revista da Universidade de Alfenas. V.4, p. 21-24, 1998.

FERREIRA, A. O. Guia prático da farmácia magistral. São Paulo: Pharmabooks Editora, 2010, 673p.

HAJI-SAEID, M., SAMPA, M. H. O., CHMIELEWSKI, A. G. Radiation treatment for sterilization of packaging materials. Radiation Physics and Chemistry, v. 76, p. 1535-1541, 2007.

JORGE, A. O. C. Princípios de biossegurança em odontologia. Revista biociência, Taubaté, v.8, n.1, p.7-17, 2002.

KALIL, E. M., COSTA, A. J. F. Desinfecção e Esterilização. ACTA ORTOPEDIA BRASILEIRA, ano 2, v. 4, 1994.

LETRARI, J.; LIMA, H. O. S.; VANIN, M. Esterilização térmica e parâmetros de morte microbiana do Bacillus tearothermophilus ATCC 7953. IV ENTEC e II WORKSHOP da UTFPR. Campus Campo Mourão- PR, Brasil, 2006.

LINE, S. J.; PICKERILL, J. K. Testing a steamformaldehyde sterizer for gas penetration efficiency. Journal of Clinical Pathology. V. 26, p. 716 - 720, 1973. 
MASTROENI, M.F. Biossegurança aplicada a laboratórios e serviços de saúde. Ed. Atheneu. São Paulo, p.160-161, 2004.

MORIYA, T., MÓDENA, J. L. P. ASSEPSIA E ANTISSEPSIA: TÉCNICAS DE ESTERILIZAÇÃO. Simpósio: FUNDAMENTOS EM CLÍNICA CIRÚRGICA - $1^{\text {a }}$ Parte. Medicina, Ribeirão Preto, ano 3, v. 41, p. 265-73, 2008.

MOZACHI, N. O hospital: Manual do ambiente hospitalar. Curitiba: Os autores, 2007. $816 p$.

PELCZAR JR, M. J., CHAN, E.C.,KRIEG, N. R. Microbiologia conceitos e aplicações. Makron Books. São Paulo. V. 1, ed. 2, p. 64-65; 194-195, 1996.

OPPERMANN, C. M.: Manual de biossegurança para serviços de saúde. PortoAlegre:PMPA/SMS/CGVS, 80p. 2003.

ROMANO, J. C. $O$ que é esterilização. Disponível em: <http://www.hospvirt.org.br/enfermagem/port/pergresp.htm>. Acesso em: 29 jul. 2012.

RUTALA, W. A. Disinfection, sterilization and waste diposal. In: WENZEL, R. P. Presention and control of nosocomial infections. Baltimore: Williams e Wilkins, cap. 18, p. 257-267, p.344345, 1987.

TRABUlSi, L. R., ALTERTHUM, F., GOMPERTZ, O. F., CANDEIAS, J. A. N. Microbiologia. São Paulo: Editora Atheneu, 1999.

YAMAMOTO, C.H.; PINTO, T.J.A.; MEURER, V.M.; CARVALHO, A.M.; REZENDE, P. Controle de Qualidade Microbiológico de Produtos Farmacêuticos, Cosméticos e Fitoterápicos Produzidos na Zona da Mata, MG. Anais do $2^{\circ}$ Congresso Brasileiro de Extensão Universitária Belo Horizonte, 2004.

ZANON, U. e NEVES, J. A importância médico social das infecções hospitalares. Revista da Sociedade Brasileira de Medicina. V.14, p. 119, 1987. 